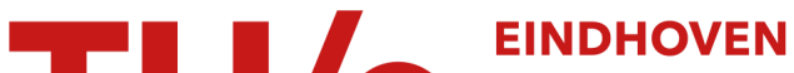 \\ UNIVERSITY OF \\ TECHNOLOGY
}

\section{Stimuli-responsive polymersomes and nanoreactors}

Citation for published version (APA):

Che, H., \& van Hest, J. C. M. (2016). Stimuli-responsive polymersomes and nanoreactors. Journal of Materials Chemistry B, 4(27), 4632-4647 . https://doi.org/10.1039/C6TB01163B

DOI:

10.1039/C6TB01163B

Document status and date:

Published: 17/07/2016

\section{Document Version:}

Accepted manuscript including changes made at the peer-review stage

\section{Please check the document version of this publication:}

- A submitted manuscript is the version of the article upon submission and before peer-review. There can be important differences between the submitted version and the official published version of record. People interested in the research are advised to contact the author for the final version of the publication, or visit the $\mathrm{DOI}$ to the publisher's website.

- The final author version and the galley proof are versions of the publication after peer review.

- The final published version features the final layout of the paper including the volume, issue and page numbers.

Link to publication

\section{General rights}

Copyright and moral rights for the publications made accessible in the public portal are retained by the authors and/or other copyright owners and it is a condition of accessing publications that users recognise and abide by the legal requirements associated with these rights.

- Users may download and print one copy of any publication from the public portal for the purpose of private study or research.

- You may not further distribute the material or use it for any profit-making activity or commercial gain

- You may freely distribute the URL identifying the publication in the public portal.

If the publication is distributed under the terms of Article $25 \mathrm{fa}$ of the Dutch Copyright Act, indicated by the "Taverne" license above, please follow below link for the End User Agreement:

www.tue.nl/taverne

Take down policy

If you believe that this document breaches copyright please contact us at:

openaccess@tue.nl

providing details and we will investigate your claim. 


\section{J. Mater. Chem. B}

\section{REVIEW}

\section{Stimuli-responsive polymersomes and nanoreactors}

Received 00th January 20xx, Accepted 00th January 20xx

DOI: $10.1039 / x 0 x \times 00000 x$

www.rsc.org/

\begin{abstract}
Hailong Che and Jan C. M. van Hest*
Macromolecular self-assembly is attracting increasing scientific interest in polymer science. One of the most studied assemblies are stimuli-responsive polymersomes that can convert specific environmental changes to functional outputs based on a physicochemical adjustment of their chain structures and membrane properties. These unique features have made it possible to design and construct smart self-assembled architectures for various emerging applications such as polymeric nanocapsules for tunable delivery vehicles. Moreover, stimuli-responsive polymersomes possess the ability to encapsulate active enzymatic species which makes them well suited as nanoreactors capable of performing enzymatic reactions. In this regard, this class of smart polymersomes provides an avenue to apply synthetic polymer systems as biomimetic materials. Here, in this review, we will highlight recent progress with regard to stimuli-responsive polymer vesicles/nanocapsules and their development towards intelligent nanocarriers and nanoreactors or artificial organelles.
\end{abstract}

\section{Introduction}

Compartmentalization is a process abundantly found in nature in order to confine, protect and regulate biological processes and to enable transport of cargo. Over the years, extensive research has been performed to create synthetic analogues of the mostly lipid-based natural compartments, for a variety of applications. There has been increasing interest in designing and constructing compartments to mimic the structure of living cells and their organelles. ${ }^{1}$ For example, fatty acids spontaneously form dynamic bilayer vesicles capable of growing and dividing which makes them ideal candidates for protocell membranes. ${ }^{2-4}$ Phospholipids are another class of appropriate components which due to their amphiphilic nature can be assembled via a wide range of methodologies into different vesicular nanostructures to create artificial cells. ${ }^{5-7}$ Despite their ability to successfully form vesicles, fatty acids and phospholipids often lack sufficient robustness due to their small bilayer thickness, which leads to low mechanical stability and leakiness. This hampers to some extent applications in the area of cargo transport and confinement. This has triggered research in the area of polymer-based selfassembled nanostructures. Amphiphilic block copolymers are able to self-assemble in aqueous solution to produce nanoobjects, analogously to lipids but with enhanced stability..$^{8-11}$ Controlled polymerisation methods such as atom transfer radical polymerization (ATRP), reversible addition-fragmentation chain transfer (RAFT) and ring-opening polymerization make it possible to prepare various types of polymers with controlled molecular weight, low polydispersity

Radboud University, Institute for Molecules and Materials, Heyendaalseweg 135, 6525 AJ, Nijmegen, The Netherlands E-mail: j.vanhest@science.ru.nl
Index (PDI) and well-defined compositions. Generally speaking, amphiphilic block copolymers can form a wide range of classical morphologies such as spherical micelles, worm-like micelles, vesicles and even tubular vesicles in block-selective solvents with appropriate polymer hydrophilic-hydrophobic balance. ${ }^{12-16}$ Among these polymeric aggregates, significant progress has been made on polymeric vesicles, often called polymersomes, with dimensions in the nanometer region presenting greater stability than liposomes. ${ }^{17}$ In principle, three factors mainly contribute to the formation of polymersomes: molecular weight, weight fraction of the hydrophilic block, and the effective interaction strength of its hydrophobic fraction with water. Polymersomes can be yielded by adjusting the hydrophilic-hydrophobic balance according to Equation (1):

$$
p=\frac{v}{a l}
$$

where $\mathrm{p}$ is the "packing parameter," $\mathrm{v}$ is the volume of the hydrophobic chains, a is the optimal area of head group, and l, the length of the hydrophobic tail. Generally, amphiphiles are more likely to form vesicles with $1 / 2 \leq p \leq 1$, while spherical micelles and cylindrical micelles can be expected to form when $p \leq 1 / 3$, and $1 / 3 \leq p \leq 1 / 2$, respectively. ${ }^{18-21}$

Over the years, polymeric vesicles have gathered much interest in the field of medical applications, because they can encapsulate not only hydrophobic or fatty molecules into their membranes but also hydrophilic compounds within the aqueous lumen, in contrast to micelles that can mainly carry hydrophobic substances (some micelles can also load hydrophilic cargo $)^{22-26}$. Some liquid crystalline cubosomes were also reported to serve as functional nanocarriers because of their high lipid volume fraction and large internal surface area for loading with both hydrophilic and lipophilic agents. ${ }^{27-29}$ 


\section{J. Mater. Chem. B}

\section{REVIEW}

Table 1 Common polymer structures used for polymersome formation which are described in this review.

\begin{tabular}{|c|c|c|}
\hline Polymer structures & Name & Abbreviations \\
\hline & Polyacrylic acid & PAA \\
\hline & Polystyrene & PS \\
\hline & Poly(4-vinylpyridine) & P4VP \\
\hline & Poly(ethylene oxide) & PEO \\
\hline & Poly(2-diethylaminoethylmethacrylate) & PDEAEMA \\
\hline & Poly(butadiene) & PBD \\
\hline & Poly(trimethoxysilyl)propylmethacrylate & PTMSPMA \\
\hline & Poly(2-dimethylaminoethyl methacrylate) & PDMAEMA \\
\hline & Poly[N-(4-vinylbenzyl)-N,N-dibutylamine & PVBA \\
\hline & Poly(N-acryloyl-L-phenylalanine) & PAP \\
\hline & Poly(L-glutamic acid) & PGlu \\
\hline & Poly(L-lysine) & PLys \\
\hline & Poly(N-isopropylacrylamide) & PNIPAM \\
\hline & Polyglycerol monomethacrylate & PGMA \\
\hline
\end{tabular}




\begin{tabular}{|c|c|c|}
\hline Polymer structures & Name & Abbreviations \\
\hline & $\begin{array}{c}\operatorname{poly}(\mathrm{N} \text {-(3-aminopropyl)methacrylamide } \\
\text { hydrochloride) }\end{array}$ & PAMPA \\
\hline & Poly(N-vinylcaprolactam) & PVCL \\
\hline & Poly(dimethylsiloxane) & PDMS \\
\hline & $\begin{array}{c}\text { Poly[trans-N-(2-ethoxy-1,3-dioxan-5-yl) } \\
\text { acrylamide] }\end{array}$ & PtNEA \\
\hline & Poly(2-methoxyethyl vinyl ether) & PMOVE \\
\hline & $\begin{array}{l}\text { Poly 1-(2-vinyloxyethyl)-3- } \\
\text { ethylimidazolium tetrafluoroborate }\end{array}$ & $\mathrm{P}\left([\mathrm{Et} \mid \mathrm{m}]\left[\mathrm{BF}_{4}\right]\right)$ \\
\hline & Poly(phenylene sulphide) & PPS \\
\hline & Poly(ethylene glycol) methacrylate & pPEGMA \\
\hline & $\begin{array}{l}\text { poly }\{\mathrm{N}-[\mathrm{N}-(2 \text {-aminoethyl)-2- } \\
\text { aminoethyl]aspartamide }\}\end{array}$ & $P[A s p(D E T)]$ \\
\hline & $\begin{array}{l}\text { Poly(nitrobenzyloxycarbonylaminoethyl } \\
\text { methacrylate) }\end{array}$ & PNBOC \\
\hline & Poly(methyl caprolactone) & $\mathrm{PMCL}$ \\
\hline & Poly[(N-amidino)dodecyl acrylamide] & PAD \\
\hline & Poly(butyl acrylate) & PBA \\
\hline & $\begin{array}{l}\text { Poly[isocyanoalanine(2-thiophene-3-yl- } \\
\text { ethyl)amide] }\end{array}$ & PIAT \\
\hline & Poly(2-methyloxazoline) & PMOXA \\
\hline & Poly(styrene boronic acid) & PSBA \\
\hline
\end{tabular}

Furthermore, polymeric nanocapsules can also serve as nanoreactors, defined as artificial organelles, by encapsulating enzymes to perform metabolic reactions. ${ }^{17}$, 30-33 In all cases membrane permeability plays an important role with regard to the applicability of the polymersomes, as the large hydrophobic domain makes it difficult to transport substances across the membrane. ${ }^{8}$, 34 For controlled drug release, or for the diffusion of substrates and products across the bilayer, appropriate approaches need to be followed to create membranes with controllable permeability. 
One of the most interesting approaches is to apply stimuli-responsive macromolecules, a class of "smart" polymers that can sense minimal changes in the environment, installed by $\mathrm{pH}$, light, temperature, enzymes, redox agents, ions, gas, mechanical force, or electrochemistry, leading to amplified physical or chemical structural changes. ${ }^{35-41}$ In the past decade, significant efforts have been made to the development of stimuliresponsive polymersomes or polymeric nanocapsules as they can receive internal or external stimuli to endow the system with functionality for controlling the capture and release of drugs and chemicals and for the performance of enzymatic reactions. ${ }^{42-47}$ Polymersomes constructed from stimuli-responsive polymers can convert external signals to functional outputs such as morphological transitions, volume contraction/expansion and membrane permeability enhancement. Additionally, some of the stimulusresponsive behaviours are similar to biological signalreactive modes, which makes research in this field of great interest from a biomimetic point of view.

This review focuses on discussing intelligent selfassembled polymeric vesicles/nanocapsules made from stimuli-responsive polymers, and their emerging and perspective applications in nanocarriers and nanoreactors that have been developed over the last years. As there have been a number of excellent reviews on stimuli-responsive polymers and polymer capsules, we mainly aim at the current progress for stimuli-responsive polymer vesicles/nanocapsules, especially the most significant developments made in the field using triggers as gas, enzymes, near-infrared (NIR) light and magnetic fields. In the second part of this review, stimuli-responsive polymer nanoreactors will be addressed. In particular, we highlight functional polymersome-based nanoreactors which are employed in enzymatic reactions with the aim to develop artificial organelles.

\section{Stimuli-responsive polymersomes}

\section{$2.1 \mathrm{pH}-$ responsive polymersomes}

$\mathrm{pH}$-responsiveness is one of the main stimuli applied in the design of responsive polymersomes. This is partly a result of the importance of $\mathrm{pH}$ variation in nature, such as the lowering of the $\mathrm{pH}$ in endosomes and lysosomes of cells to promote degradation of biomacromolecules. Furthermore, $\mathrm{pH}$-responsive systems can be conveniently realized by the use of polyacid or polybase polymers whose hydrophilic-hydrophobic transition can be switched by $\mathrm{pH}$ gradients.

Early work on $\mathrm{pH}$-sensitive vesicles was initiated by Einsenberg's group on triblock copolymer vesicles of poly(acrylic acid)-b-polystyrene-b-poly(4-vinylpyridine) (PAA- $b$-PS- $b$-P4VP). ${ }^{48}$ Going from low $\mathrm{pH}$ to high $\mathrm{pH}$, the aggregate morphologies of this triblock copolymer changed progressively from vesicles, to solid spherical or ellipsoidal aggregates, and finally back to vesicles (Fig.1). This vesicle composed of an asymmetric membrane demonstrated $\mathrm{pH}$ triggered inversion with preferentially segregated acidic and basic coronas by control of the repulsive interaction among corona chains under different $\mathrm{pH}$ conditions. Based on this work, they reported a three-layered polymersome from triblock copolymer poly(ethylene oxide)-b-PS-bpoly(2-diethylamino ethyl methacrylate) $\left(\mathrm{PEO}_{45}-b-\mathrm{PS}_{130}-b\right.$ PDEAEMA ${ }_{120}$ ) that possessed a $\mathrm{pH}$-induced "breathing" feature. ${ }^{49}$ When the $\mathrm{pH}$ was decreased from 10.4 to 3.4 , a cracking of the rigid PS layer and a sharp increase of the vesicle size and the wall thickness were observed due to the progressive swelling of the PDEAEMA layer. These "breathing" vesicles gave rise to high permeability to water and high rates of proton diffusion. More importantly, this process was highly reversible with a relaxation time of ca. 1 min by changing the $\mathrm{pH}$ between 10.4 and 3.4. The PS hydrophobic layer ensured that the vesicles retained their shape. Chiu's group found that polymersomes constructed from random copolymers of acrylic acid (AA) and distearin acrylate (DSA) possess $\mathrm{pH}$-responsive transmembrane channels. ${ }^{50}$ When the $\mathrm{pH}$ was increased to 6.5 , AA was ionized and permeable channels were created as a result of the abrupt disruption of hydrogen bonds and hydrophobic association of un-ionized AA units. These interesting vesicles can be operated as artificial organelles without the incorporation of channel-forming proteins.

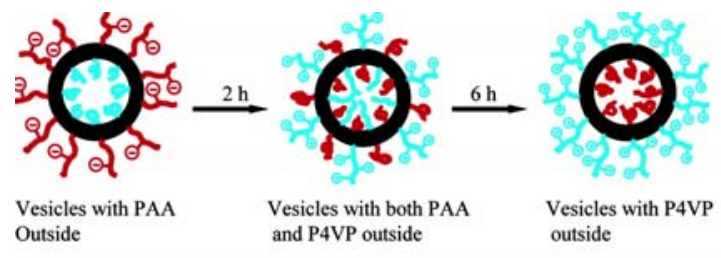

Fig.1 Schematic representation of $\mathrm{pH}$-triggered inversion of PAA- $b$-PS- $b$-P4VP vesicles. ${ }^{48}$

Armes and co-workers reported that the membrane permeability of $\mathrm{pH}$-responsive polymersomes composed of the self-crosslinkable copolymer PEO- b- [PDEAEMA -stat-3(trimethoxysilyl) propyl methacrylate] (PEO-b-P(DEAEMA stat-TMSPMA) can be tuned by $\mathrm{pH} .{ }^{51}$ Crosslinking was accomplished by the reaction of the trimethoxysilyl groups after hydrolysis into a siloxane network. At low $\mathrm{pH}$, protonated PDEAEMA blocks led the membrane to swell, along with increasing permeability. Crosslinking was in this case required in order to prevent the vesicles from disassembling, due to the low Tg of the hydrophobic block employed. Also, they found that higher degrees of crosslinking resulted in lower wall permeabilities.

Recently, crosslinked polymersomes were successfully employed by our group to form a water-in-oil Pickering emulsion. ${ }^{52,53}$ Polymersomes composed of PAA-b-P(S-co-4vinyl benzyl azide) were stabilized by a Cu-assisted azide alkyne conjugation reaction with a bis-alkyne reagent. The polymersomes were able to form and stabilize water/oil Pickering emulsions and disassemble to the dispersed state in aqueous solution under acidic and neutral $\mathrm{pH}$, 
respectively. Using this method, the surface of the polymersomes exposed to the water phase was successfully modified by gold and platinum nanoparticles to form Janus polymersomes when the polymersomes were positioned at the water/oil interface in the Pickering emulsion (Fig.2). This simple and efficient approach to Janus polymersomes opens up perspectives for the use of these structures in applications where anisotropic properties are demanded.

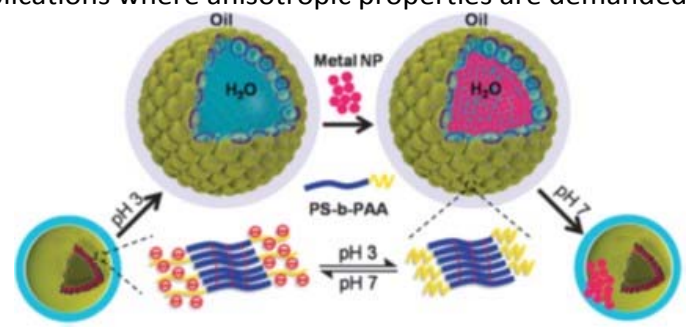

Fig.2 Fabrication process of Janus polymersomes (JP) by $\mathrm{pH}$ responsive polymersome Pickering emulsion (PPE) formation and disassembly. ${ }^{52}$

Amphiphilic block copolymers composed of polypeptides are a versatile class of stimulus-responsive building blocks for the self-assembly into vesicles. ${ }^{54} \mathrm{~A}$ change in $\mathrm{pH}$ can not only introduce a change in ionization state, but it can also lead to conformational changes, which can give rise to porous membranes. Two kinds of polypeptides have been used to construct $\mathrm{pH}$-responsive polymersomes: hybrid block copolymers where the polypeptide serves as hydrophobic and the synthetic polymer as the hydrophilic block, or block copolymers in which both the hydrophilic and hydrophobic blocks are polypeptides.

Deming's group successfully used $\mathrm{pH}$ to control the conformation of non-ionic block copolypeptide vesicles of L-leucine and ethylene glycol-modified L-lysine residues, PLeu-b-PEGLys. At high $\mathrm{pH}$, uncharged poly(L-lysine) was not water soluble, and preferentially adopted the $\alpha$-helical conformation, leading to the formation of vesicles. However, at $\mathrm{pH}=3$, protonation of the amino side-chains on the lysine residues enhanced their hydrophilicity and destabilized the $\alpha$-helical structure because of electrostatic repulsion of the like charges. This $\mathrm{pH}$-triggered helix-to-coil conformation transition destabilised the vesicular assembly, giving rise to porous membranes. Lecommandoux and co-workers developed $\mathrm{pH}$-responsive vesicles by a zwitterionic block copolypeptide, PGlu ${ }_{15}-b$ PLys $_{15} .{ }^{55}$ At acidic $\mathrm{pH}$, the poly(L-glutamic acid) block was neutralized, and its secondary conformation changed from a charged coil to a neutral and more compact R-helical structure, accompanied with a decrease in solubility. Under basic conditions, the protonated poly(L-lysine) block $\left(-\mathrm{NH}_{3}{ }^{+}\right)$ was transformed into a neutral and insoluble domain, forming the core of the aggregates. This kind of schizophrenic vesicles was reversibly produced in moderate acidic or basic aqueous solutions from the polypeptide diblock copolymers. O'Reilly's group found similar "schizophrenic" behaviour in the $\mathrm{pH}$-responsive block copolymer, PDEAEMA-b-poly(N-acryloyl-L-phenylalanine)
(PDEAEMA -b-PAP). The polymersomes were able to switch their coronas and membranes by simple direct dissolution or solvent switching of the prepared copolymer in water at acidic and basic conditions. ${ }^{56} \mathrm{pH}$ variation has also been used to trigger a change in the secondary structure of hybrid polypeptide-based polymersomes such as PBD- $b$ PLys and PI- $b$-PLys. ${ }^{57-59}$ From these examples it is clear that changing membrane properties as a function of $\mathrm{pH}$ has become a well-established methodology that can be potentially used for the controlled release of encapsulated drugs. In particular the peptide-based systems show much promise, as these vesicles are composed of fully biodegradable constituents.

Besides changing membrane permeability changes in $\mathrm{pH}$ can also lead to variations in shape of the vesicular structures. Zhang's group demonstrated the ability of $\mathrm{pH}$ induced morphological transitions employing the $\mathrm{pH}$ sensitive $A B C$ triblock copolymer poly(dimethyl acrylamideb-PS-b-poly[N-(4-vinylbenzyl)-N,N-dibutylamine] (PDMA-bPS-b-PVBA). ${ }^{60}$ Because of the appending dibutylamine groups, the core-forming block PVBA was $\mathrm{pH}$-sensitive which upon ionization became soluble in acidic aqueous medium. At a certain critical length of the PVBA block and at sufficiently low $\mathrm{pH}$ (4.5), this polarity switch was strong enough to induce a nanoparticle-to-vesicle morphology transition, the process being called an in-to-out switch. A rapid transition of aggregation state was also observed for PAA- $b$-PBD polymeric vesicles, which were transformed into worms and spheres by changing $\mathrm{pH} .{ }^{61}$

\subsection{Temperature-responsive polymersomes}

Temperature is another stimulus that can be used to trigger the specific responsiveness of polymersomes. For example, a well-known temperature-responsive polymer PNIPAM is often introduced into functional block polymer systems to produce temperature-sensitive self-assemblies. PNIPAM can transit between hydrophilic to hydrophobic when the temperature is switched around its lower critical solution temperature (LCST) of $32{ }^{\circ} \mathrm{C}$, which is at a physiologically relevant temperature. When PNIPAM is applied as the hydrophobic part of a polymer system it can self-assemble to form stable vesicles at the normal body temperature of $37{ }^{\circ} \mathrm{C}$ (higher than the LCST), while disassemble and rapidly release encapsulated substances at temperatures below 32 ${ }^{\circ} \mathrm{C}$.

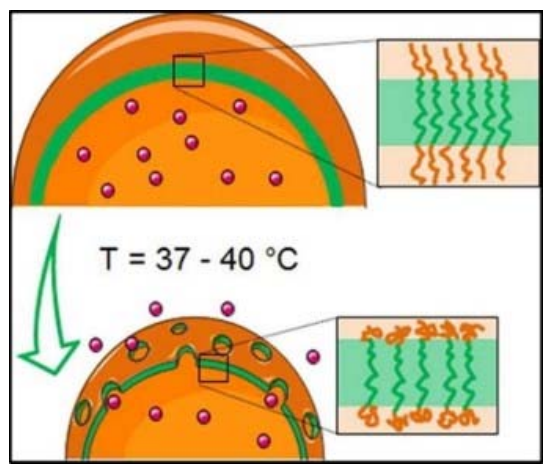


Fig.3 Temperature-sensitive polymersomes for controlled delivery of anticancer drugs. ${ }^{62}$

This concept was demonstrated by Yang et al. using diblock copolymer PEO- $b$-PNIPAM. ${ }^{63}$ These polymersomes were used as smart nanocarriers by encapsulating both hydrophilic drugs into the aqueous lumen and hydrophobic molecules into their membranes, while allowing temperature-controlled quick release of both types of compounds below $32{ }^{\circ} \mathrm{C}$. McCormick's group prepared poly(N-(3-aminopropyl)methacrylamide hydrochloride)-bPNIPAM (PAMPA- $b$-PNIPAM) and poly(2(dimethylamino)ethyl methacrylate)-b-PNIPAM (PDMAEMA-b-PNIPAM) that could form temperatureresponsive aggregrates in water. ${ }^{64,} 65$ The hydrophilic PAMPA block was ionically crosslinked through the addition of an oppositely charged polyelectrolyte. The PDMAEMA- $b$ PNIPAM based vesicles were stabilized by the reduction of $\mathrm{NaAuCl}_{4}$ to form hybrid aggregates with $\mathrm{Au}$ nanoparticles embedded in the PDMAEMA domain. These polymersomes are highly promising as smart carriers for triggered intracellular delivery of biopharmaceutics such as pDNA, siRNA, pharmaceutical proteins and peptides. More recently, polymersomes composed of a novel type of temperature-sensitive triblock copolymer poly( $\mathrm{N}$-vinyl caprolactam)-b-polydimethylsiloxane- $b$-poly(N-vinyl caprolactam) ( $\left.\mathrm{PVCL}_{n}-b-\mathrm{PDMS}_{65}-b-\mathrm{PVCL}_{n}\right)$ were reported. ${ }^{62}$ At elevated temperatures, transient pores created in the PVCL- $b$-PDMS- $b$-PVCL membrane enabled DOX to easily pass through the hydrophobic PDMS layer without damaging the vesicles. Such polymersomes have shown temperature-controlled permeability within the physiologically relevant temperature range of $37-42{ }^{\circ} \mathrm{C}$ which could be used for sustained delivery of anticancer drugs (Fig. 3).

O'Reilly's group have reported thermally induced micelle to vesicle morphology transitions of amphiphilic block copolymers.66, 67 They synthesised PNIPAM containing diblock copolymers that were able to self-assemble into nano-objects in aqueous solution. These nano-objects could undergo a relatively fast and fully reversible transition from micelle to vesicle morphologies (Fig. 4). This transition could be performed at $40{ }^{\circ} \mathrm{C}$ in purely aqueous or mixed aqueous /organic environments and the transition time could also be tuned.

Except for single temperature-responsive vesicles, there are also a number of reports on dual responsive polymersome systems. ${ }^{68,69}$ For example, Li and co-workers used a series of well-defined diblock copolymers PEO- $b$ poly[trans-N-(2-ethoxy-1,3-dioxan-5-yl) acrylamide] (PEO- $b$ PtNEA) to prepare double $\mathrm{pH}$ and temperature responsive polymersomes. ${ }^{70}$ The morphologies of the formed aggregates could be tuned from spherical nanoparticles to well dispersed polymersomes depending on the temperature and $\mathrm{pH}$ of the system. Upon heating above the CAT (critical aggregation temperature) of the PtNEA blocks, these copolymers could form aggregates of various morphologies ranging from spherical nanoparticles to well dispersed polymersomes, depending on the chain length of PtNEA and the polymer concentration. These nano-objects were stable at physiological $\mathrm{pH}$ but gradually disassembled in mildly acidic medium due to the acid-triggered hydrolysis behaviour of PtNEA. More recently, temperature and UVresponsive pillararene-based supra-amphiphilic polypseudorotaxanes were constructed from a watersoluble pillar[7]arene and an azobenzene containing random copolymer, which self-assembled to form vesicles in water (Fig. 5). ${ }^{71}$ Upon irradiation with UV light at $365 \mathrm{~nm}$ for over $1 \mathrm{~h}$ or heating the solution, the vesicles disassembled and the membrane started to disrupt into solid nanospheres. However, the disassembled system could be reassembled by irradiation with visible light at 435 $\mathrm{nm}$ or cooling the solution. Reversible transformations between solid nanospheres and vesicles were thus successfully achieved by adjusting the solution temperature or UV-visible light irradiation because of the thermoresponsiveness of the pillararene and the photoresponsiveness of the azobenzene unit.

Although less common also polymers that possess upper critical solution temperature (UCST) behaviour have been employed for vesicle formation. These polymers become soluble upon heating and their UCST is strongly governed by their molecular weight and concentration. ${ }^{72}$ UCST-type poly(2-methoxyethyl vinyl ether)-b-poly 1-(2-vinyloxyethyl)3-ethylimidazolium tetrafluoroborate (PMOVE- $b$ $\mathrm{P}([\mathrm{Et} / \mathrm{m}][\mathrm{BF} 4]))$ polymers were prepared by living cationic polymerization. Polymersomes were formed above the phase separation temperature $\left(T_{\mathrm{ps}}\right)$ of the poly(MOVE) segment, whereas micelles were formed below the $T_{\mathrm{ps}}$ of $\mathrm{P}\left([\right.$ EtIm] $[\mathrm{BF} 4]){ }^{73}$

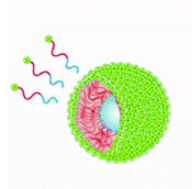

Micelles

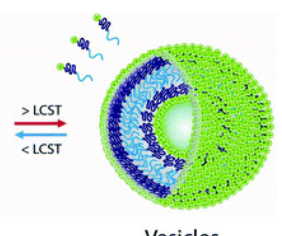

Vesicles
Fig.4 Schematic representation of the thermally induced micelle to vesicle morphology transition of assemblies of the diblock copolymer poly( $t$-butyl acrylate)-b-poly $(\mathrm{N}$ isopropyl acrylamide) (PtBuA- $b$-PNIPAM). ${ }^{67}$

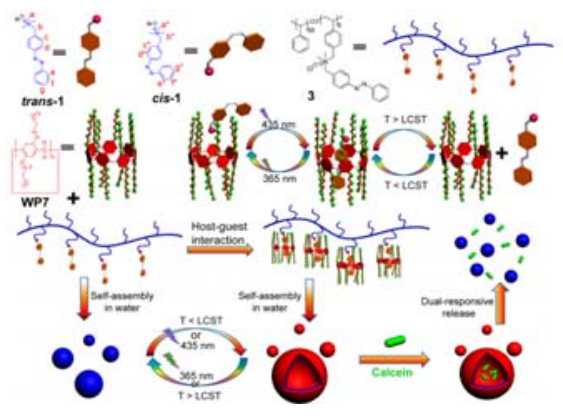


Fig.5 Chemical structures of pillar[7]arene and an azobenzene containing random copolymer and illustration of the dual-responsive controlled assembly and disassembly..$^{71}$

\subsection{Redox-sensitive polymersomes}

Redox potentials vary greatly in the intracellular and extracellular environment, and between tumor and normal tissue. In the cytosol and nuclei, the concentration of one of the most prominent reducing agents, glutathione (GSH)is much higher $(10 \mathrm{mM})$ than in the extracellular environment $(2-20 \mu \mathrm{M}){ }^{74}$ Therefore, taking advantage of the local redox state, reduction or oxidation of responsive polymers can be used to change the properties of polymersome membranes to endow these compartments with novel functions.

In many papers, disulfide linkages are applied in reduction-responsive polymer assemblies. ${ }^{75-77}$ For example, the reduction-sensitive block copolymeric macroamphiphile PEG-SS-PPS (PPS: poly(phenylene sulphide) was used to develop nanocarriers with specific sensitivity and fast response to the reducing environment of the endosome. ${ }^{78}$ Koul and co-workers used sensitive polymersomes based on the amphiphilic triblock copolymer pPEGMA-PCL-SS-PCLpPEGMA (pPEGMA: poly((ethylene glycol) methacrylate)) as nanocarriers. ${ }^{79}$ The intracellular tripeptide glutathione triggered the degradation of the polymersomes due to the cleavage of the disulfide groups in the polymeric backbone. The redox-responsive biocompatible polymersomes exhibited enhanced antitumor efficacy and are promising candidates for intracellular drug delivery in cancer therapy. Besides reduction-induced disassembly, also shape changes could be achieved under the influence of a reducing agent. Kataoka's group prepared a series of block copolymers (PEG-SS-P(Asp), PEG-SS-P [Asp(DET)] and PEG$P[A s p(D E T)]) \quad(P(A s p): \quad$ poly(aspartic acid), $\mathrm{P}($ Asp(DET):poly $\{\mathrm{N}$-[N-(2-aminoethyl)-2-aminoethyl]

aspartamide\}) which were assembled into polyion complex micelles (PICmicelles) due to the electrostatic attractions between the two different polymers. Upon cleavage of the disulfide bonds with dithiothreitol (DTT) a micelle-to-vesicle transition was observed(Fig. 6). ${ }^{80}$

There have been few reports on oxidation-responsive polymersomes which are commonly based on reactive oxygen species (ROS) e.g. hydrogen peroxide $\left(\mathrm{H}_{2} \mathrm{O}_{2}\right)$, which originates from the aerobic metabolism. The first block used in oxidation-responsive polymersomes was PPS which functioned as the hydrophobic block in the vesicle membrane. ${ }^{81}$ The addition of $\mathrm{H}_{2} \mathrm{O}_{2}$ converted the hydrophobic PPS to hydrophilic poly(propylene sulphoxide), resulting in increasing curvature of the hydrophobichydrophilic interface along with the phase transformation from vesicles to micelles. This class of oxidation-responsive polymersomes proved to be promising as nanocontainers in drug delivery, biosensing and biodetection. Based on this work, Hubbell and co-workers applied PPS containing polymersomes as oxidation-sensitive carriers for both antigen and adjuvant delivery to dendritic cell (DC) endosomes. ${ }^{82}$ When toll-like receptor agonists gardiquimod or R848 were loaded within the polymersomes, the ability of gardiquimod to induce IL-6 and IL-12 cytokine expression showed a 10-fold enhancement which makes it possible to use these oxidation-sensitive polymersomes as a vaccine delivery platform for inducing cell-mediated antigen-specific immune response.

Ferrocene-containing polymers are another class of oxidation-responsive polymers that have been extensively studied recently. Ferrocene-decorated polymers are usually utilized to develop oxidation-responsive systems based on host-guest interactions. Yuan's group reported a pseudoblock copolymer based on cyclodextrin end-functionalized PS and ferrocene-modified PEO via orthogonal assembly. ${ }^{83}$ These two end-decorated homopolymers self-assembled into polymersomes in aqueous solution which displayed assembly and disassembly behaviour because of the reversible association and disassociation controlled by electrochemistry: Fc was oxidized into charged PEO- $\mathrm{Fc}^{+}$ upon exposure to $+1.5 \mathrm{~V}$ to disaggregate the vesicles into small fragments, the reduction of PEO-Fc ${ }^{+}$at $-1.5 \mathrm{~V}$ enabled the association of this polymer with PS- $\beta-C D$ again (Fig. 7), which led to the reformation of the polymer vesicles.

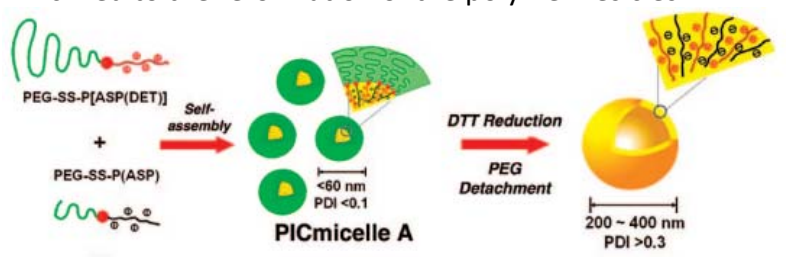

Fig. 6 Schematic representation of reduction-induced micelle-vesicle transitions. ${ }^{80}$

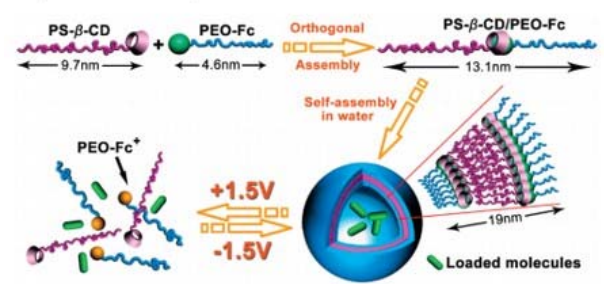

Fig.7 Reversible assembly and disassembly of PS- $\beta-C D$ /PEO-Fc controlled by electrochemistry. ${ }^{83}$

\subsection{Light-responsive polymersomes}

Photo-responsive self-assembled systems have attracted great interest because the responsiveness of the assemblies can be rapidly and conveniently induced at a specific time and location upon exposure to wavelengths which can be visible light, ultraviolet, and near-infrared. ${ }^{84-88}$ These systems are commonly based on the principle that photosensitive moieties are incorporated in polymers that function as light-cleavable linkers, undergo light-induced degradation or light-responsive conformational changes, such as azobenzene. 
Liu's group have prepared amphiphilic PEO- $b$-PNBOC (PNBOC: poly(nitrobenzyloxy carbonyl aminoethyl methacrylate) to develop UV-regulated "traceless" crosslinked polymersomes. ${ }^{89} \mathrm{UV}$ irradiation triggered selfimmolative decaging releasing primary amine moieties, yielding poly(2-aminoethyl methacrylate) accompanied with the release of 2-nitrobenzaldehyde and $\mathrm{CO}_{2}$. The resulting amine moieties were shown to undergo an amidation reaction in the membrane between $\mathrm{pH} 7.4$ and 4.5 , leading to vesicle crosslinking instead of vesicle-tounimer disassembly (Fig. 8). Interestingly, the crosslinking process was accompanied with the generation of residual protonated amines which led to a hydrophobicity-tohydrophilicity transition of the polymersome membrane. Thus, upon UV irradiation, hydrophilic network channels were generated through the bilayer membrane which were used to achieve light-regulated membrane permeabilization and co-release of both hydrophilic and hydrophobic substances. Other self-immolative polymersomes (SIPsomes) were prepared from PBC-b-PDMA (PBC: poly(benzyl carbamate) PDMA: $\operatorname{poly}(N, N$-dimethyl acrylamide) polymers which exhibit stimuli-triggered headto-tail cascade depolymerization features. ${ }^{90}$ The selfimmolative block was caged with perylen-3-yl, 2nitrobenzyl, or disulfide moieties, which are responsive to visible light (420 nm), UV light (365 $\mathrm{nm}$ ) or reductive milieu. The SIPsomes were disintegrated into water-soluble 4aminobenzyl alcohol (ABA), carbon dioxide, and PDMA, which allowed these polymersomes to be used for controlled drug co-release. By loading substrates and enzymes in different polymersomes that respond to different triggers, only when both triggers were applied enzymatic conversion could be observed (Fig. 9). Besides this so-called AND gate system, also OR gates were developed. Meier and co-workers designed PMCL-ONBPAA (PMCL: poly(methyl caprolactone) amphiphilic photocleavable block copolymers which self-assembled into polymersomes. ${ }^{91}$ These polymersomes disintegrated upon UV irradiation, yielding small micellar-like structures, and simultaneously releasing their payload which meets the requirements for intelligent drug delivery systems.

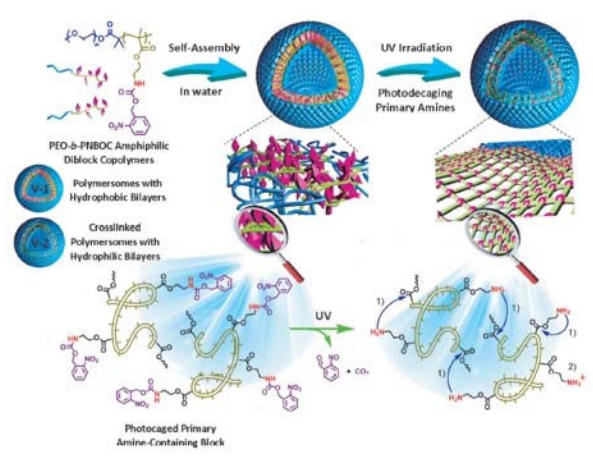

Fig.8 Light-responsive polymersomes exhibiting concurrent phototriggered "traceless" crosslinking and vesicle membrane permeabilization. ${ }^{89}$

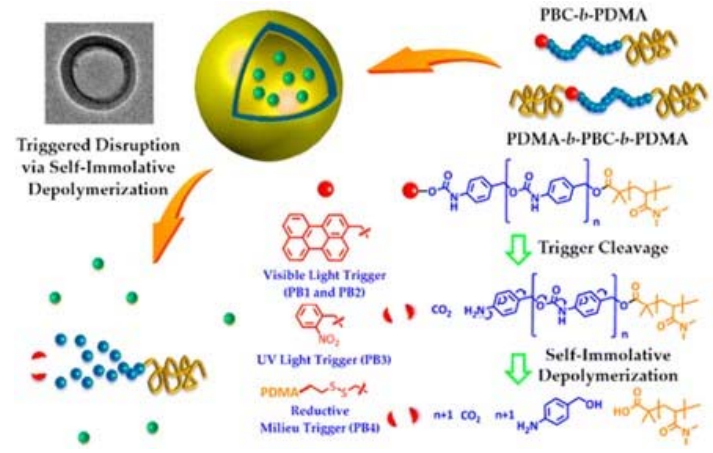

Fig. 9 Schematic illustration of SIPsomes self-assembled from PBC-b-PDMA amphiphilic block copolymers which are subjected to self-immolative depolymerization into small molecules upon cleavage of "capping" moieties. ${ }^{86}$

Dendritic block copolymers have also been used to form light-responsive polymersomes. A series of amphiphilic linear-dendritic block copolymers (LDBCs) containing a PEG linear segment connected to fourth generation dendrons containing 4-isobutyloxyazobenzene units (AZO) were synthesized and the responsiveness of the self-assembled vesicles was explored.92 A faster and more efficient photoinduced isomerization of AZO was achieved by decreasing azobenzene content in the codendrons, which led to drastic structural changes and deformed vesicles with a distorted membrane upon irradiation. As a result the permeability of the vesicle was increased and the trans-tocis photoisomerization of AZO could thus be utilized to trigger the release of both hydrophilic (Rhodamine B) and hydrophobic (Nile Red) compounds. Also, the self-assembly and controlled degradation of dendritic polymersomes (dendrimersomes) containing first through third generation (G1-G3) photodegradable hydrophobic blocks was studied. ${ }^{93}$

Host-guest systems containing light-sensitive species have also been explored for photo-responsive self-assembly. ${ }^{94,95}$ Bilayer vesicles consisting of hydrophilic pillar[6]arene and trans azobenzene-based amphiphilic polymers were formed via host-guest interactions. The switchable trans-cis transition of AZO upon applying UV and visible light affected the host-guest interaction, resulting in a reversible transformation from vesicle (trans configuration) to micelle (cis configuration). ${ }^{94}$

Near-Infrared (NIR) light sensitive self-assemblies are ideal systems and extremely promising for clinical applications because of their great advantages such as deeper tissue penetration, lower scattering properties, and minimal harm to tissues. ${ }^{96-98} \mathrm{Nie}$ and co-workers have used a microfluidic platform to prepare polymersomes containing gold nanoparticles (GNPs) with controlled dimensions and morphology. ${ }^{99}$ The GNPs were incorporated into the membrane and $671 \mathrm{~nm}$ laser irradiation was used to excite the gold-loaded vesicles (GVs), producing heat in the vicinity of cancer cells. Simultaneously, the heating dissociated the photosensitizer Ce6-loaded GVs and led to 
the release of the Ce6 substrate to produce singlet oxygen, killing cancer cells (Fig. 10). The NIR light-responsive polymersomes were shown to have excellent theranostic capability without noticeable toxicity, and are highly promising for image-guided synergistic photothermal and photodynamic therapy (PTT/PDT) of tumors in vivo. In another example Au nanoflowers (AuNFs) were loaded in the membrane of PEO- $b-P S$ polymersomes. ${ }^{100}$ The significant increase in the absorption of the vesicles because of the strong plasmon coupling of the AuNFs led to responsiveness of the vesicles to NIR light. The molecules encapsulated in the polymersomes were released in a remote-controlled model using NIR light.

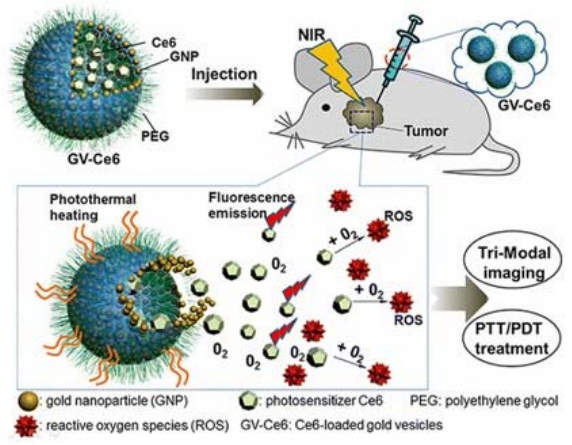

Fig.10 Photosensitizer-loaded gold NP vesicles with strong plasmonic coupling effect for image-guided photothermal/photodynamic (PTT/PDT) therapy. ${ }^{99}$

\subsection{Gas-responsive polymersomes}

Recently, polymers that have the ability to respond to bioactive molecules or utilize intracellular signaling molecules as stimuli have become a topic of interest in biomimetic chemistry and polymersome research. Wellknown intracellular biosignals such as $\mathrm{NO}, \mathrm{CO}_{2}, \mathrm{H}_{2} \mathrm{~S}$ and $\mathrm{O}_{2}$ have been reported to manipulate polymer self-assembly when the appropriate stimuli-responsive polymers were applied and potential intracellular applications were demonstrated, such as bioimaging, diagnostics and drug/gene delivery. ${ }^{41,101-103}$

Yuan's group reported $\mathrm{CO}_{2}$-responsive macromolecules and their applications in shape transformation, smart surfaces and controlled drug release. ${ }^{104-109}$ They successfully developed "breathing" vesicles from the $\mathrm{CO}_{2}-$ responsive amidino-containing diblock copolymer PEO- $b$ PAD(PAD: Poly[( $\mathrm{N}$-amidino)dodecyl acrylamide]). The size and volume of these polymersomes was tuned by alternating treatment with $\mathrm{CO}_{2}$ and $\mathrm{Ar}$ through the protonation and deprotonation effect (Fig. 11). ${ }^{104}$ These polymersomes with unique gas-responsivity were shown to have reversible distinctive expansion and contraction, therefore they can be regarded as functional "breathing" nanocontainers for periodically accelerating drug release. Based on this work, Zhao's group studied the $\mathrm{CO}_{2}$-driven self-assembly and shape transformation of PEO- $b$-PAD with a broad range of shapes. ${ }^{110}$ Self-assembled microscopic tubules were successfully transformed into submicroscopic vesicles and nano-micelles with increasing $\mathrm{CO}_{2}$ stimulus time, which adjusted the copolymer hydrophilichydrophobic ratio. PDMAEMA and PDEAEMA are another type of $\mathrm{CO}_{2}$-responsive polymers. The tertiary amine groups in PDEAEMA and PDMAEMA can react with $\mathrm{CO}_{2}$ in water, exhibiting an extended hydrophilic chain conformation, and this process is reversible upon exposure to $\mathrm{N}_{2}$ to remove $\mathrm{CO}_{2} .{ }^{111-114}$ Triblock copolymer PEO- $b$-PS- $b$-PDEAEMA was synthesized and used to construct a series of $\mathrm{CO}_{2}$-sensitive self-assembled nanostructures (spherical micelles, wormlike micelles, and vesicles) and their gas-triggered shape transformation. ${ }^{115}$

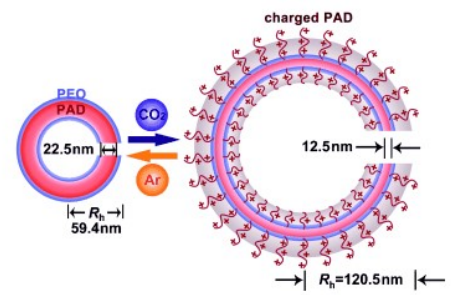

Fig. 11 Schematic representation of the self-assembly of diblock copolymer PEO- $b$-PAD into vesicles and their reversible gas-responsive "breathing" in aqueous media as $\mathrm{CO}_{2}$-responsive polymersomes. ${ }^{104}$

Except for $\mathrm{CO}_{2}$-responsive block copolymers, there have been also reports on $\mathrm{CO}_{2}$-responsive systems based on host-guest interactions. Zhao et al. developed a $\mathrm{CO}_{2}$ sensitive imidazole-containing supramolecular block glycopolypeptide. ${ }^{116}$ They found that benzimidazole-ended poly(L-valine) and CD-functionalized dextran can selfassemble, driven by host-guest interactions, into vesicles or nanofibers depending on the poly(L-valine) length. The vesicular and fibrous structures underwent a reversible disassembly process upon "breathing in" $\mathrm{CO}_{2}$ and assembly upon "breathing out" $\mathrm{CO}_{2}$ because of the $\mathrm{CO}_{2}$ responsiveness of the benzimidazole unit (Fig.12). This system provides the possibility to develop virus-like particles for bioapplications, such as gene delivery. Huang's group demonstrated that the pillararene-based molecular recognition motif established from a water-soluble pillar[5]arene and an anionic surfactant sodium dodecyl sulfonate (SDS) also have $\mathrm{CO}_{2}$ responsiveness. ${ }^{117}$ Upon protonation by $\mathrm{CO}_{2}, 10$ tertiary amine groups containing water-insoluble Pillar[5]arene were turned into watersoluble species which could accept an anionic surfactant SDS to form vesicles. Furthermore, upon bubbling with $\mathrm{N}_{2}$ to eliminate $\mathrm{CO}_{2}$, vesicle disruption was induced. Upon protonation by $\mathrm{CO}_{2}, 10$ tertiary amine groups of the waterinsoluble pillar[5]arene were turned into water-soluble species which can accept an anionic surfactant SDS to form vesicles. Furthermore, upon bubbling with $\mathrm{N}_{2}$ to eliminate $\mathrm{CO}_{2}$, vesicle disruption was induced.

Hydrogen sulfide $\left(\mathrm{H}_{2} \mathrm{~S}\right)$, generated from L-cysteine via cystathionine $\mathrm{Y}$-lyase (CSE) mediated decomposition, is another very important neuromodulator and cell signalling molecule. ${ }^{118}$ Recently, Yan's group have built a $\mathrm{H}_{2} \mathrm{~S}$ - 
responsive system based on an azidomethylbenzoate (AzMB)-containing block copolymer. ${ }^{103} \mathrm{AzMB}$ is an $\mathrm{H}_{2} \mathrm{~S}$ sensitive molecule and can be converted into benzylamine, resulting in a series of intramolecular cascade reactions to exhibit self-immolative behaviour. Therefore, upon exposure to $\mathrm{H}_{2} \mathrm{~S}, \mathrm{AzMB}$ containing PEO-b-PAGMA vesicles were subject to a controlled disassembly process (Fig.13). Moreover, the CSE enzyme, capable of converting intracellular Cys into $\mathrm{H}_{2} \mathrm{~S}$, was successfully encapsulated into the vesicle membrane to construct a responsive nanovehicle for controlled drug delivery. This kind of stimulus mode will provide a new avenue to develop endogenous-responsive nanocapsules for biological applications.

Interestingly, polymers sensitive to both $\mathrm{CO}_{2}$ and $\mathrm{O}_{2}$ have been prepared. $\mathrm{O}_{2}$-responsive 2,2,2-trifluoroethyl methacrylate (FMA) was incorporated into $\mathrm{CO}_{2}$-responsive polymer systems. With $\mathrm{O}_{2}$ bubbling, the PEO- $b$-(PFMA-coPDEAEMA) polymersomes expanded eight times in volume because interactions between $\mathrm{O}_{2}$ molecules and the pentafluorophenyl groups can enhance water solubility of the highly hydrophobic PFMA block; $\mathrm{CO}_{2}$ bubbling enabled the vesicles to transform into small spherical micelles due to the increasing interfacial free energy. ${ }^{102}$

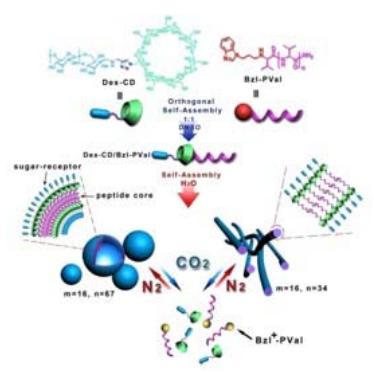

Fig.12 Orthogonal connection of benzimidazole-ended poly(L-valine) (BzI-PVal) and CD-functionalized dextran (Dex-CD) to form supramolecular block glycopolypeptides and schematic of their $\mathrm{CO}_{2}$-switchable assembly and disassembly behavior. ${ }^{116}$

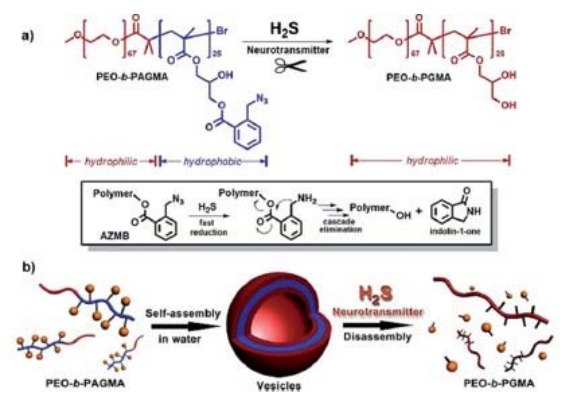

Fig.13 (a) $\mathrm{H}_{2} \mathrm{~S}$-responsive cleavage of PEO-b-PAGMA and the $\mathrm{H}_{2} \mathrm{~S}$-induced cascade reaction mechanism. (b) $\mathrm{H}_{2} \mathrm{~S}$ responsive controlled disassembly process. ${ }^{103}$

\subsection{Enzyme-responsive polymersomes}

Enzyme-responsive polymers can cue unique properties in polymeric materials, as a result of the high level of selectivity and efficiency accompanied by enzymatic conversions. ${ }^{119}$ Specific enzymatic reactions have been utilized to develop smart supramolecular systems that are switched between assembled and disassembled structures. Most reports have dealt with enzyme sensitive micelles for controlled drug release and transport, the number of enzyme-responsive polymersomes is still limited.

Heise et al. constructed biohybrid PBA- $b$-P(Glu-co-Ala) vesicles consisting of block copolymers of poly(L-glutamic acid) copolymerized with various quantities of L-alanine by $\mathrm{N}$-carboxyanhydride ring opening polymerization. ${ }^{120}$ When the self-assembled vesicular structures were exposed to the enzymes elastase and thermolysin, the polymersomes were degraded depending on the composition of the hydrophilic and hydrophobic block. PBA containing block copolymers possessing $50 \% \mathrm{~L}$-alanine in the polypeptide block showed a high degradation response compared to polymers containing lower L-alanine quantities. Amphiphilic copolypeptides containing a hydrophobic precursor diblock copolypeptide, poly(L-methionine $)_{65}$ - $b$-poly(L-leucine ${ }_{0.5}-$ stat-L-phenyl alanine $\left.0_{0.5}\right)_{20}$ and a segment of water-soluble methionine sulfoxide $\left(\mathrm{M}^{\circ}\right)$ was created by Deming's group. ${ }^{121}$ This polymer self-assembled into vesicles, with $\mathrm{M}^{\mathrm{O}}$ being substrate for reductase enzymes. The hydrophilic $\mathrm{M}^{\mathrm{O}}$ segments in the vesicles were converted to hydrophobic poly(L-methionine) (M) segments upon exposure to these enzymes. The generated hydrophobic $M$ segments led to a change in assembly from spherical to a crumpled sheet-like morphology which resulted in vesicle membrane curvature and release of cargo.

Enzyme-responsive polymersomes are ideal candidates for drug delivery vehicles because certain enzymes are overexpressed in pathological regions such as at tumor and inflammation sites, and both hydrophilic and hydrophobic drugs can be encapsulated. Dextran-based vesicles were developed and water-soluble molecules like Rhodamine-B (Rh-B) and the polyaromatic anticancer drug camptothecin (CPT) were selectively loaded in the hydrophilic lumen and hydrophobic membrane, respectively. Esterase enabled the cleavage under physiological conditions of the aliphatic ester with which the dextran moiety was connected enabling fast release of CPT or Rh-B (Fig. 14). ${ }^{122}$ More importantly, the drug-loaded polymersomes demonstrated significantly better cellular uptake compared to free CPT and they were seen to localize in the perinuclear region of the cells. This versatile polymeric carrier provides new research means for dual encapsulation and delivery of hydrophilic and hydrophobic drug molecules.

Noncovalent host-guest interactions can also be introduced into enzyme-responsive systems. Liu and coworkers have reported an enzyme-responsive vesicle constructed from p-sulfonatocalix[4]-arene as the macrocyclic host and natural enzyme-cleavable myristoylcholine as the guest molecule. ${ }^{123}$ The formed vesicles were specifically and efficiently dissipated by cholinesterase, overexpressed in Alzheimer's disease, endowing fast release behaviour of entrapped water- 
soluble drugs. The enzyme-induced cleavage of myristoylcholine can be extended to various enzyme tuned self-assembled materials.

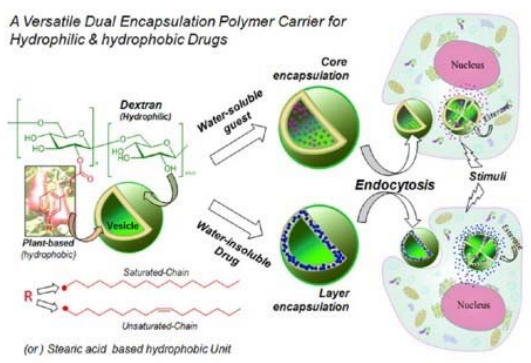

Fig. 14 Dextran vesicular approach for delivery of hydrophilic and hydrophobic drugs (or molecules) into cells. ${ }^{122}$

\subsection{Magnetic Field-responsive polymersomes}

Magnetic field sensitive systems have broad applications for therapy, imaging, and diagnosis because of the unique properties of magnetic fields, such as their noninvasive nature, high penetration, absence of energy dissipation and ease of control. The introduction of paramagnetic or superparamagnetic materials into self-assembled systems would provide a new approach to achieve magnetoresponsive properties in drug delivery. ${ }^{124-126}$ Magnetic fieldresponsive systems are susceptible to magnetic guidance, induced temperature increase, or a combination of both.

Lecommandoux and co-workers have studied magnetic field triggered drug release from polymersomes for cancer therapeutics. ${ }^{127}$ Using poly(trimethylene carbonate)- $b$ poly(L-glutamic acid) (PTMC- $b$-PGA) block copolymers, they successfully encapsulated DOX together with hydrophobic surface-modified superparamagnetic iron oxide nanoparticles (USPIO; $\gamma-\mathrm{Fe}_{2} \mathrm{O}_{3}$ ) within polymersomes. Such polymersomes were shown to have deformation behaviour of the vesicle membrane when exposed to an alternating magnetic field (HAMF). The high-frequency HAMF enabled USPIOs to generate localized heating which changed the crystallinity of PTMC and increased the polymersomes' permeability, giving rise to increased drug release.

$\mathrm{Fe}_{3} \mathrm{O}_{4}$ nanoparticles were incorporated into the bilayer membrane of $\mathrm{P}_{2} \mathrm{VP}_{66}-b-\mathrm{PEO}_{44}$ polymersomes. ${ }^{128}$ The hydrophobic nanoparticles were not located in the center of the bilayer but rather at the periphery decorating the hydrophobic/hydrophilic interface because of the low entropy of mixing between particles and polymers. The loaded $\mathrm{Fe}_{3} \mathrm{O}_{4}$ nanoparticles resulted in a tendency to bridge to adjacent bilayers leading to the formation of oligo- and multilamellar vesicles. Moreover, the encapsulation of magnetic nanoparticles improved the magnetophoretic mobility under external magnetic fields due to the increased lamellarity of the vesicles.

Magnetic field-responsive systems cannot only be constructed via the encapsulation of magnetic nanoparticles into polymersomes, diamagnetic structures assembled from amphiphilic block copolymers can also be utilized for magnetic manipulation. Our group reported a series of polymer stomatocytes based on PEG-b-PS copolymers via an osmotically driven shape transformation. ${ }^{129-131}$ It was found that the size of their opening increased along with increasing the intensity of the magnetic field and this process was reversible when the magnetic field was removed (Fig. 15). ${ }^{132}$ The mechanism of magnetic field-modulated opening of the stomatocytes was caused by the highly anisotropic magnetic susceptibility of the building blocks, PEG- $b$-PS, which resulted in their collective perpendicular alignment in the magnetic field. This led to stretching of the membrane, resulting in a deformation of the structure and increase in the opening. 132, 133 This novel magnetic field-responsive stomatocytes with switchable size of the opening might offer new possibilities for capture and release of cargo via the reversible magnetic valve, although one of the current limitations of the methodology is that the PS membrane has to be plasticized by organic solvent to allow the shape transformation to take place.

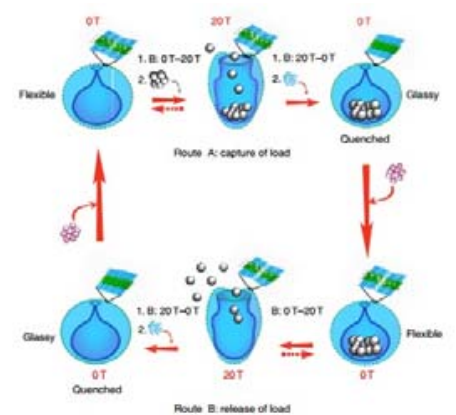

Fig.15 Schematic representation of the strategy for capture and release of cargo with stomatocyte magneto-valves. ${ }^{132}$

\section{Stimuli-responsive nanoreactors}

Beside application as drug release systems, a further biomimetic step towards developing functional compartments is to encapsulate enzymes inside polymersomes as nanoreactors or artificial organelles, which are able to mimic metabolic reactions. As we mentioned above, polymer-based capsules are more stable compared to liposomes, however the improved stability is at the same time a disadvantage because of the poor membrane permeability. This is an obvious issue when enzymatic reactions are to be performed inside polymersomes due to the difficulty of transporting chemicals through the polymer membrane barrier. ${ }^{34}$ In this regard, approaches have to be introduced to improve the permeability, making exchange of substrate and product possible, while enclosing enzymes inside polymersomes without leakage. For example, a limited number of block polymers such as PS- $b$-PIAT (PIAT: poly[isocyanoalanine(2thiophene-3-yl-ethyl)amide]) are able to self-assemble into permeable polymersomes, due to the frustrated packing of the molecules in the polymer bilayer. ${ }^{134-136}$ Channel proteins like outer-membrane-protein $\mathrm{F}(\mathrm{OmpF})$, were incorporated into PDMS-PMOXA-PDMS (PMOXA: Poly(2methyloxazoline)) membranes to render polymersomes with porosity. ${ }^{137}$ The abovementioned examples are intrinsically permeable polymersomes, of which the porosity and thus the activity cannot be regulated. A more bio-inspired and versatile approach is the use of stimuliresponsive polymersomes with enhanced permeability 
under environmental changes. In this section, we highlight progress in the development of nanoreactors based on stimuli-responsive polymersomes.

We reported a polymersome nanoreactor with controlled permeability induced by $\mathrm{pH}$ and sugar-responsive block copolymers. ${ }^{138}$ The polymersome was composed of a mixture of PEG- $b$-PS and boronic acid containing polymer PEG- $b$-PSBA (PSBA: poly(styrene boronic acid). When boronic acid was ionized to boronate in alkaline media, the solubility of the PSBA block in water increased, which was further enhanced by the binding of glucose or fructose to the boronic acid moiety. An optimal amount of PEG- $b$-PSBA was used as a minor component and mixed with PEG- $b$-PS to co-assemble into polymersomes. Upon raising $\mathrm{pH}$ and with the introduction of glucose, the hydrophobic PSBA block was converted to a hydrophilic domain and could be removed, thereby creating pores that allowed substrate to enter and be converted by enzymes encapsulated in the nanoreactors (Fig. 16). The permeability and porosity of the polymersomes could be tuned by varying the ratio between PEG- $b$-PS and PEG- $b$-PSBA.

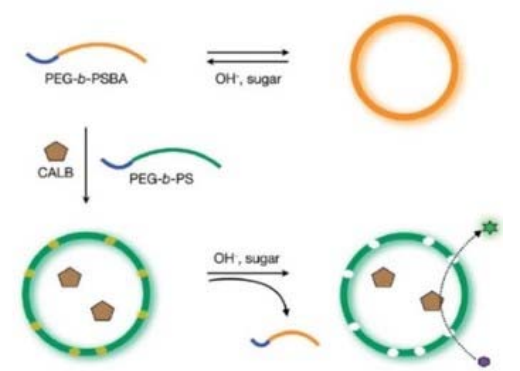

Fig.16 Schematic representation of the formation of bioreactors with a permeable membrane utilizing the sugar responsiveness of the block copolymer PEG-b-PSBA. ${ }^{138}$

Yuan et al. devised a $\mathrm{CO}_{2}$-responsive polymersome with controlled permeability upon addition or removal of $\mathrm{CO}_{2}$ from the self-assembled vesicles. ${ }^{105} 105$ Amphiphilic block copolymer PEO-b-PAD self-assembled into polymersomes which could self-expand when exposed to $\mathrm{CO}_{2}$ due to transformation of the PAD chains from an unprotonated, entangled state to a protonated, stretched state. The $\mathrm{CO}_{2}-$ induced polymersome swelling adjusted membrane permeability and enabled the controlled release of nanoparticles depending on the degree of membrane pore size. Furthermore, myoglobin ( $\mathrm{Mb}$ ) was encapsulated inside the polymersomes to create a nanoreactor (Fig. 17). When $\mathrm{CO}_{2}$ was passed through the solution for $5 \mathrm{~min}$, the dilated membrane channels permitted GSH to travel through the bilayer to react with $\mathrm{Mb}$ generating $\mathrm{O}_{2}$-carrying myoglobin (oxyMb). Upon prolongation of the $\mathrm{CO}_{2}$ stimulus to $15 \mathrm{~min}$, the vesicles were further swollen and the channels further opened; as a result, trypsin was able to go through the membrane hydrolysing $\mathrm{Mb}$. Through the control of $\mathrm{CO}_{2}$ levels, these $\mathrm{CO}_{2}$-responsive smart polymersomes with controlled permeability can isolate two different enzymatic reactions and provide the possibility to mimic cytomembranes and cellular functions.

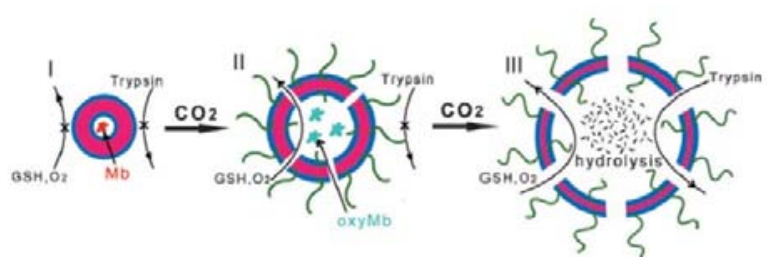

Fig. 17 Illustration of the compartmentalization of two enzymatic reactions in the PEG- $b$-PAD polymersomes modulated by $\mathrm{CO}_{2}$ levels. ${ }^{105}$

Recently, Palivan and co-workers created $\mathrm{pH}$-responsive nanoreactors by a biomimetic strategy using synthetic membranes equipped with channel proteins, OmpF. ${ }^{139}$ $\mathrm{PMOXA}_{6}-\mathrm{PDMS}_{44}-\mathrm{PMOXA}_{6}$ polymersomes were modified with OmpF which was chemically modified with a $\mathrm{pH}$ responsive molecular cap to serve as "gate". Thus, the opening and closing of OmpF "gates" reconstituted in the polymersome membrane was highly $\mathrm{pH}$-controlled. The blockage/free diffusion of molecules through the porin channel could be better tuned depending on the $\mathrm{pH}$ values of the environment of the polymersomes to control enzymatic activity inside the nanoreactors (Fig.18). They found that the activity of horseradish peroxidase (HRP) inside these nanoreactors was much higher at $\mathrm{pH}=5.5$ than at $\mathrm{pH}=7.4$, indicating $\mathrm{pH}$ controlled in situ enzymatic activity. This system offers a new approach to the design of artificial organelles capable of responding "on demand".

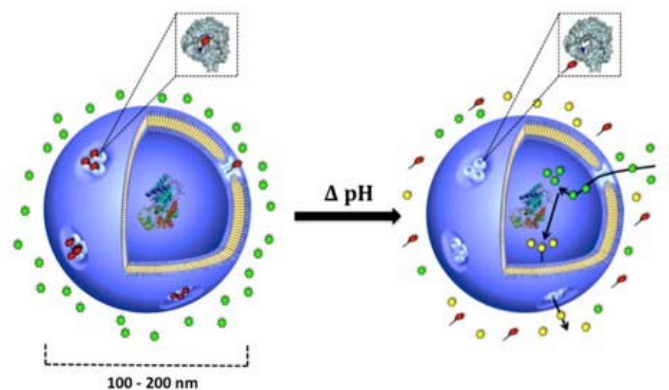

Fig. 18 Schematic representation of the $\mathrm{pH}$-triggered enzymatic activity inside nanoreactors modified wth protein "gate". ${ }^{139}$

Bruns and co-workers developed a simple and versatile method to generate UV-responsive nanoreactors by encapsulating a hydroxyalkylphenone within a polymersome membrane. ${ }^{140}$ They used $\alpha, \omega$-hydroxy-endcapped PMOXA- $b$-PDMS- $b$-PMOXA, $\quad \alpha, \omega$-acrylate-endcapped PMOXA- $b$-PDMS- $b$-PMOXA, and PEO- $b$-PB polymer mixtures to prepare polymersomes. The two latter polymers, containing double bonds at the chain ends or in the PB block, are prone to be attacked by radicals and could potentially undergo cross-linking reactions. The watersoluble photo-initiator 2-hydroxy-4-2-(hydroxyethoxy)-2methylpropiophenone (PP-OH), an $\alpha$-hydroxyalkylphenone, was incorporated into the polymersome membranes. Upon UV irradiation two primary radicals were formed (ketyl and alcohol) which reacted with the block copolymers in the polymersome membranes, leading to chemical modification of the polymers with the hydrophilic PP-OH, which therefore caused an increase in the permeability of the polymersomes. HRP was encapsulated inside the 
polymersomes to create nanoreactors and the permeabilized nanoreactors retained their ability to protect encapsulated biocatalysts from degradation by proteases (Fig. 19).

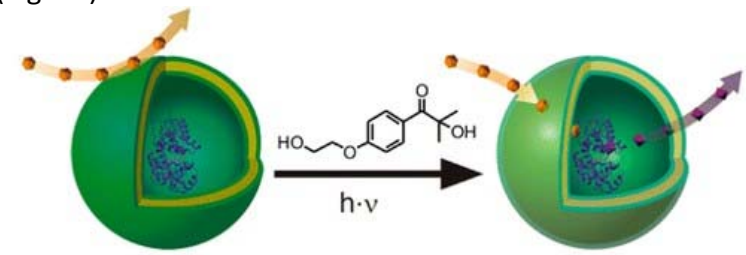

Fig. 19 Illustration of the photoreaction of a hydroxyalkyphenone with the membrane of polymersomes: a versatile method to generate semipermeable photoresponsve nanoreactors. ${ }^{140}$

In order to realize a reversible permeability-enhancing process, Liu et al. proposed a novel strategy for facile, switchable, and reversible regulation of polymersome bilayer permeability. ${ }^{141}$ A spiropyran-based monomer, containing a unique carbamate linkage (SPA), was introduced in the amphiphilic block copolymer PEO- $b$-PSPA to generate photochromic polymersomes. Hydrophilic zwitterionic merocyanine (MC) states were obtained from SP moieties upon light irradiation with $\lambda_{1}<420 \mathrm{~nm}$ and MC polymersomes showed switched-on permeability along with stability because of the hydrophobic and hydrogen bonding interactions and zwitterionic and $\pi-\pi$ stacking interactions. This photoisomerization process was reversible under light irradiation with $\lambda_{2}>450 \mathrm{~nm}$, transforming the vesicles back into original SP polymersomes with switched-off permeability (Fig. 20). These polymersomes with light-switched on/off permeability can be used to modulate microcapsule reactors. They encapsulated a non-fluorescent thiolresponsive probe inside the internal aqueous cavity which was converted to a highly fluorescent thiol-reacted product in the presence of thiol-containing molecules such as cysteine. The fluorescence emission of the probe greatly increased after being irradiated with $405 \mathrm{~nm}$ laser light due to the diffusion of cysteine across the polymer membrane.

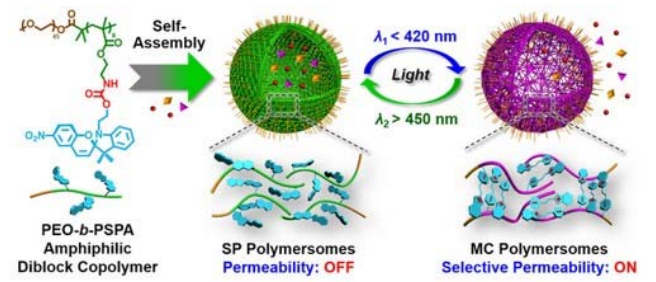

Fig. 20 Photochromic polymersomes with light-switched reversible on/off permeability. ${ }^{141}$

It is worth mentioning that, although a large number of stimuli-responsive polymersomes have been designed and constructed, only a few of them have been investigated and used as nanoreactors. When polymersomes are intended to serve as artificial organelles, activity of encapsulated enzymes should be triggered in a controlled and ondemand manner. In this respect, there is still a wide space and great challenge for scientists, especially for polymer researchers to develop and explore more versatile stimuliresponsive systems to generate functional nanoreactors.

\section{Conclusion and perspective}

In this review article, we have put a spotlight on recent developments in stimuli-responsive polymersomes and their applications in constructing various delivery systems as well as nanoreactors. Taking advantage of specific changes in the micro-environment of biological systems, stimuli-responsive polymersomes are attractive candidates as delivery vehicles or nanoreactors with site specific activity control. Changing the hydrophilic-hydrophobic balance in a controlled manner renders polymersomes with "intelligence" such as morphological transitions, volume contraction/expansion and membrane permeability enhancement. We have also focused on the application of stimuli-responsive polymersomes as nanoreactors to mimic functional organelles with controlled metabolic activities. The main goal of these stimuli-responsive nanoreactors is that their activity is under control of certain functionalities that lead to membrane responsiveness and permeability. This principle has been demonstrated for $\mathrm{pH}$, light, $\mathrm{CO}_{2}$ and sugar responsive nanoreactors with triggered activity of encapsulated enzymes.

The diverse stimuli-responsive polymersomes summarized in this review would be able to serve as polymeric drug carriers and provide a great deal of possibilities for different controlled release applications. Moreover, recent developments in the application of new stimuli responsive polymersomes (gas, enzymes, magnetic fields) have demonstrated that selective sources of stimulation can lead to more unique or prominent features compared to other traditional chemical or physical stimuli. Also, it would be possible to endow these polymersomes with biomimetic cellular biological functions to create synthetic organelles and simple cell structures. However, the future development of stimuli-responsive polymersomes faces the challenge to move forward towards more practical applications than pure conceptual ones, which for example requires the usage of biodegradable and biocompatible polymer building blocks with similar responsiveness. More attention should be paid to construct novel stimuliresponsive macromolecular systems with specific structures, controlled porosity and enzyme activity. Additionally, localisation of stimuli-responsive nanoreactors inside cells is still an issue, and new approaches should be developed to transport these smart polymersomes into the cytosol and make them serve their purpose as artificial organelles in dysfunctional cells.

From a longer term perspective, it can be expected that multi-stimulus-responsive polymersomes will act as intracellular drug reservoirs, which release their content over prolonged periods of time whenever the cell sends out the desired signal, and only in quantities that are necessary to counteract the stimulus. As such, a real on-demand delivery of therapeutics can be achieved, if for example a change in $\mathrm{pH}$ or reductive potential is induced. This regulatory behaviour is of course also applicable to nanoreactors carrying therapeutic enzymes. Stimulusresponsive polymersomes can also be applied in extracellular applications, for example in communication with and activation of immune cells. In this case it is worth exploring the ability of these structures to change their shape and membrane permeability, thereby affecting the 
interaction surface and the release of cytokines in a manner that can optimize the immune response.

\section{Acknowledgements}

The authors would like to acknowledge the Dutch Science Foundation (NWO, $\mathrm{VICl}$ grant) and the Dutch Ministry of Education, Culture and Science (Gravitation program 024.001.035) for funding.

\section{Notes and references}

1. J. W. Szostak, D. P. Bartel and P. L. Luisi, Nature, 2001, 409, 387-390.

2. T. F. Zhu and J. W. Szostak, J. Am. Chem. Soc., 2009, 131, 5705-5713.

3. S. S. Mansy, J. P. Schrum, M. Krishnamurthy, S. Tobe, D. A. Treco and J. W. Szostak, Nature, 2008, 454, 122125.

4. I. Budin, A. Debnath and J. W. Szostak, J. Am. Chem. Soc., 2012, 134, 20812-20819.

5. R. J. Brea, M. D. Hardy and N. K. Devaraj, Chem.-Eur. J., 2015, 21, 12564-12570.

6. S. Subramaniam, E. Fahy, S. Gupta, M. Sud, R. W. Byrnes, D. Cotter, A. R. Dinasarapu and M. R. Maurya, Chem. Rev., 2011, 111, 6452-6490.

7. S. Mashaghi, T. Jadidi, G. Koenderink and A. Mashaghi, Int. J. Mol. Sci., 2013, 14, 4242.

8. D. E. Discher and A. Eisenberg, Science, 2002, 297, 967-973.

9. S. Egli, H. Schlaad, N. Bruns and W. Meier, Polymers, 2011, 3, 252-280.

10. Y. Zhao, F. Sakai, L. Su, Y. Liu, K. Wei, G. Chen and M. Jiang, Adv. Mater., 2013, 25, 5215-5256.

11. Y. Zhou and D. Yan, J. Am. Chem. Soc., 2005, 127, 10468-10469.

$12 . \quad$ Z. Li, E. Kesselman, Y. Talmon, M. A. Hillmyer and T. P. Lodge, Science, 2004, 306, 98-101.

13. M. C. van Oers, F. P. Rutjes and J. C. van Hest, J. Am. Chem. Soc., 2013, 135, 16308-16311.

$14 . \quad$ D. A. Christian, A. Tian, W. G. Ellenbroek, I. Levental, K. Rajagopal, P. A. Janmey, A. J. Liu, T. Baumgart and D. E. Discher, Nat. Mater., 2009, 8, 843-849.

15. H. Cui, Z. Chen, S. Zhong, K. L. Wooley and D. J. Pochan, Science, 2007, 317, 647-650.

16. X. Wang, G. Guerin, H. Wang, Y. Wang, I. Manners and M. A. Winnik, Science, 2007, 317, 644-647.

17. P. Tanner, P. Baumann, R. Enea, O. Onaca, C. Palivan and W. Meier, Acc. Chem. Res., 2011, 44, 1039-1049.

18. F. Chécot, S. Lecommandoux, Y. Gnanou and H. A. Klok, Angew. Chem. Int. Ed., 2002, 41, 1339-1343.

19. X. Chen, X. Ding, Z. Zheng and Y. Peng, New. J. Chem., 2006, 30, 577-582.

20. H.-J. Choi and C. D. Montemagno, Nano Lett., 2005, 5, 2538-2542.

21. A. Feng and J. Yuan, Macromol Rapid Commun., 2014, 35, 767-779.
22. C. G. Palivan, R. Goers, A. Najer, X. Zhang, A. Car and W. Meier, Chem. Soc. Rev., 2016, 45, 377-411.

23. C. Sanson, O. Diou, J. Thevenot, E. Ibarboure, A. Soum, A. Brûlet, S. Miraux, E. Thiaudière, S. Tan and A. Brisson, ACS Nano, 2011, 5, 1122-1140.

24. C. Sanson, C. Schatz, J.-F. Le Meins, A. Soum, J. Thévenot, E. Garanger and S. Lecommandoux, J. Control. Release, 2010, 147, 428-435.

25. M. SangáKim and D. SungáLee, Chem. Commun., 2010, 46, 4481-4483.

26. K. Nakashima and P. Bahadur, Adv. Colloid Interface Sci., 2006, 123-126, 75-96.

27. J. Y. Chong, X. Mulet, A. Postma, D. J. Keddie, L. J. Waddington, B. J. Boyd and C. J. Drummond, Soft matter, 2014, 10, 6666-6676.

28. S. Deshpande, E. Venugopal, S. Ramagiri, J. R. Bellare, G. Kumaraswamy and N. Singh, ACS Appl. Mat. Interfaces, 2014, 6, 17126-17133.

29 C. D. Driever, X. Mulet, L. J. Waddington, A. Postma, H. Thissen, F. Caruso and C. J. Drummond, Langmuir, 2013, 29, 12891-12900.

30. S. Chuanoi, Y. Anraku, M. Hori, A. Kishimura and K. Kataoka, Biomacromolecules, 2014, 15, 2389-2397.

31. D. Dobrunz, A. C. Toma, P. Tanner, T. Pfohl and C. G. Palivan, Langmuir, 2012, 28, 15889-15899.

32. K. T. Kim, S. A. Meeuwissen, R. J. Nolte and J. C. van Hest, Nanoscale, 2010, 2, 844-858.

33. K. Renggli, P. Baumann, K. Langowska, O. Onaca, N. Bruns and W. Meier, Adv. Funct. Mater., 2011, 21, 1241-1259.

34. M. Marguet, L. Edembe and S. Lecommandoux, Angew. Chem. Int. Ed., 2012, 124, 1199-1202.

35. S. Dai, P. Ravi and K. C. Tam, Soft Matter, 2008, 4, 435449.

36. J.-F. Gohy and Y. Zhao, Chem. Soc. Rev., 2013, 42, 7117-7129.

37. M. Huo, J. Yuan, L. Tao and Y. Wei, Polym. Chem., 2014, 5, 1519-1528.

38. J. Hu, G. Zhang and S. Liu, Chem. Soc. Rev., 2012, 41, 5933-5949.

39. C. de las Heras Alarcón, S. Pennadam and C. Alexander, Chem. Soc. Rev., 2005, 34, 276-285.

40. A. E. Smith, X. Xu and C. L. McCormick, Prog. Polym. Sci., 2010, 35, 45-93.

41. Q. Yan and Y. Zhao, Chem. Commun., 2014, 50, 1163111641.

42. A. K. Boal, F. Ilhan, J. E. DeRouchey, T. Thurn-Albrecht, T. P. Russell and V. M. Rotello, Nature, 2000, 404, 746748.

43. C. G. Claessens and J. F. Stoddart, J. Phys. Org. Chem., 1997, 10, 254-272.

44. J. T. Davis and G. P. Spada, Chem. Soc. Rev., 2007, 36, 296-313.

45. J. A. Elemans, A. E. Rowan and R. J. Nolte, J. Mater. Chem., 2003, 13, 2661-2670.

46. W. Krijgsman, F. Hilgen, I. Raffi, F. Sierro and D. Wilson, Nature, 1999, 400, 652-655.

47. J. K. Hirschberg, L. Brunsveld, A. Ramzi, J. A. Vekemans, R. P. Sijbesma and E. Meijer, Nature, 2000, 407, 167-170.

48. F. Liu and A. Eisenberg, J. Am. Chem. Soc., 2003, 125, 15059-15064. 
49. S. Yu, T. Azzam, I. Rouiller and A. Eisenberg, J. Am. Chem. Soc., 2009, 131, 10557-10566.

50. H. C. Chiu, Y. W. Lin, Y. F. Huang, C. K. Chuang and C. S. Chern, Angew. Chem. Int. Ed., 2008, 47, 1875-1878.

51. J. Du and S. P. Armes, J. Am. Chem. Soc., 2005, 127, 12800-12801.

52. Z. Wang, F. P. J. T. Rutjes and J. C. M. van Hest, Chem. Commun., 2014, 50, 14550-14553.

53. Z. Wang, M. van Oers, F. P. Rutjes and J. van Hest, Angew. Chem. Int. Ed., 2012, 124, 10904-10908.

54. M.-H. Li and P. Keller, Soft Matter, 2009, 5, 927-937.

55. J. Rodríguez-Hernández and S. Lecommandoux, J. Am. Chem. Soc., 2005, 127, 2026-2027.

56. J. Du and R. K. O'Reilly, Macromol. Chem. Phys., 2010, 211, 1530-1537.

57. R. Sigel, M. Losik and H. Schlaad, Langmuir, 2007, 23 7196-7199.

58. K. E. Gebhardt, S. Ahn, G. Venkatachalam and D. A. Savin, J. Colloid Interf. Sci., 2008, 317, 70-76.

59. F. Chécot, J. Rodriguez-Hernandez, Y. Gnanou and S. Lecommandoux, Biomol. Eng., 2007, 24, 81-85.

60. X. Xiao, S. He, M. Dan, F. Huo and W. Zhang, Chem. Commun., 2014, 50, 3969-3972.

61. Y. Geng, F. Ahmed, N. Bhasin and D. E. Discher, J. Phys. Chem. B, 2005, 109, 3772-3779.

62. F. Liu, V. Kozlovskaya, S. Medipelli, B. Xue, F. Ahmad, M. Saeed, D. Cropek and E. Kharlampieva, Chem. Mater., 2015, 27, 7945-7956.

63. S. Qin, Y. Geng, D. E. Discher and S. Yang, Adv. Mater. 2006, 18, 2905-2909.

64. Y. Li, B. S. Lokitz and C. L. McCormick, Angew. Chem. Int. Ed., 2006, 45, 5792-5795.

65. Y. Li, A. E. Smith, B. S. Lokitz and C. L. McCormick, Macromolecules, 2007, 40, 8524-8526.

66. A. O. Moughton, J. P. Patterson and R. K. O'Reilly, Chem. Commun., 2011, 47, 355-357.

67. A. O. Moughton and R. K. O'Reilly, Chem. Commun. 2010, 46, 1091-1093.

68.

M. T. Savoji, S. Strandman and X. X. Zhu, Soft Matter, 2014, 10, 5886-5893.

69. M. T. Savoji, S. Strandman and X. X. Zhu, Langmuir, 2013, 29, 6823-6832.

70. Z.-Y. Qiao, R. Ji, X.-N. Huang, F.-S. Du, R. Zhang, D.-H. Liang and Z.-C. Li, Biomacromolecules, 2013, 14, 1555 1563.

71. X. Chi, X. Ji, D. Xia and F. Huang, J. Am. Chem. Soc. 2015, 137, 1440-1443

72. T. Aoki, M. Kawashima, H. Katono, K. Sanui, N. Ogata, T. Okano and Y. Sakurai, Macromolecules, 1994, 27, 947-952.

73. H. Yoshimitsu, E. Korchagina, A. Kanazawa, S. Kanaoka, F. Winnik and S. Aoshima, Polym. Chem., 2016.

74. R. Cheng, F. Feng, F. Meng, C. Deng, J. Feijen and Z. Zhong, J. Control. Release, 2011, 152, 2-12.

75. S. Aleksanian, B. Khorsand, R. Schmidt and J. K. Oh, Polym. Chem., 2012, 3, 2138-2147.

76. Y. Yan, Y. Wang, J. K. Heath, E. C. Nice and F. Caruso, Adv. Mater., 2011, 23, 3916-3921.

77. Z.-Q. Yu, J.-T. Sun, C.-Y. Pan and C.-Y. Hong, Chem Commun., 2012, 48, 5623-5625.

78. S. Cerritelli, D. Velluto and J. A. Hubbell, Biomacromolecules, 2007, 8, 1966-1972.
79. A. Kumar, S. V. Lale, S. Mahajan, V. Choudhary and V. Koul, ACS Appl. Mat. Interfaces, 2015, 7, 9211-9227.

80. W.-F. Dong, A. Kishimura, Y. Anraku, S. Chuanoi and K. Kataoka, J. Am. Chem. Soc., 2009, 131, 3804-3805.

81. A. Napoli, M. Valentini, N. Tirelli, M. Müller and J. A. Hubbell, Nat. Mater., 2004, 3, 183-189.

82. E. A. Scott, A. Stano, M. Gillard, A. C. Maio-Liu, M. A. Swartz and J. A. Hubbell, Biomaterials, 2012, 33, 62116219.

83. Q. Yan, J. Yuan, Z. Cai, Y. Xin, Y. Kang and Y. Yin, J. Am. Chem. Soc., 2010, 132, 9268-9270.

84. Q. Yan, J. Hu, R. Zhou, Y. Ju, Y. Yin and J. Yuan, Chem Commun., 2012, 48, 1913-1915.

85. N. Fomina, C. McFearin, M. Sermsakdi, O. Edigin and A. Almutairi, J. Am. Chem. Soc., 2010, 132, 9540-9542.

86. Z. Feng, L. Lin, Z. Yan and Y. Yu, Macromol Rapid Commun., 2010, 31, 640-644.

87. B. Yan, J.-C. Boyer, N. R. Branda and Y. Zhao, J. Am. Chem. Soc., 2011, 133, 19714-19717.

88. J. Cao, S. Huang, Y. Chen, S. Li, X. Li, D. Deng, Z. Qian, L. Tang and Y. Gu, Biomaterials, 2013, 34, 6272-6283.

89. X. Wang, G. Liu, J. Hu, G. Zhang and S. Liu, Angew. Chem. Int. Ed., 2014, 53, 3138-3142.

90. G. Liu, X. Wang, J. Hu, G. Zhang and S. Liu, J. Am. Chem. Soc., 2014, 136, 7492-7497.

91. E. Cabane, V. Malinova, S. Menon, C. G. Palivan and W. Meier, Soft Matter, 2011, 7, 9167-9176.

92. E. Blasco, J. L. Serrano, M. Piñol and L. Oriol, Macromolecules, 2013, 46, 5951-5960.

93. A. Nazemi and E. R. Gillies, Chem. Commun., 2014, 50, 11122-11125.

94. D. Xia, G. Yu, J. Li and F. Huang, Chem. Commun., 2014 50, 3606-3608.

95. D. Hu, H. Peng, Y. Niu, Y. Li, Y. Xia, L. Li, J. He, X. Liu, X. Xia and Y. Lu, J. Polym. Sci. A Polym., 2015, 53, 750760.

96. G. Liu, W. Liu and C.-M. Dong, Polym. Chem., 2013, 4, 3431-3443.

97. Q. Zhang, N. R. Ko and J. K. Oh, RSC Advances, 2012, 2, 8079-8086.

98. L. Sun, Y. Yang, C. M. Dong and Y. Wei, Small, 2011, 7 401-406.

99. J. Lin, S. Wang, P. Huang, Z. Wang, S. Chen, G. Niu, W. Li, J. He, D. Cui and G. Lu, ACS Nano, 2013, 7, 53205329.

100. J. He, P. Zhang, T. Babu, Y. Liu, J. Gong and Z. Nie, Chem. Commun., 2013, 49, 576-578.

101. J. Hu, M. R. Whittaker, H. Duong, Y. Li, C. Boyer and T. P. Davis, Angew. Chem. Int. Ed., 2014, 53, 7779-7784.

102. Q. Zhang and S. Zhu, ACS Macro Lett., 2014, 3, 743746.

103. Q. Yan and W. Sang, Chem. Sci., 2016, 7, 2100-2105.

104. Q. Yan, R. Zhou, C. Fu, H. Zhang, Y. Yin and J. Yuan, Angew. Chem. Int. Ed., 2011, 123, 5025-5029.

105. Q. Yan, J. Wang, Y. Yin and J. Yuan, Angew. Chem. Int. Ed., 2013, 52, 5070-5073.

106. A. Feng, C. Zhan, Q. Yan, B. Liu and J. Yuan, Chem. Commun., 2014, 50, 8958-8961.

107. H. Che, M. Huo, L. Peng, T. Fang, N. Liu, L. Feng, Y. Wei and J. Yuan, Angew. Chem. Int. Ed., 2015, 54, 89348938. 
108. H. Che, M. Huo, L. Peng, Q. Ye, J. Guo, K. Wang, Y. Wei and J. Yuan, Polym. Chem., 2015, 6, 2319-2326.

109. J. Guo, N. Wang, J. Wu, Q. Ye, C. Zhang, X.-H. Xing and J. Yuan, J. Mater. Chem. B, 2014, 2, 437-442.

110. Q. Yan and Y. Zhao, Angew. Chem. Int. Ed., 2013, 52, 9948-9951.

111. D. Han, X. Tong, O. Boissière and Y. Zhao, ACS Macro Lett., 2011, 1, 57-61.

112. B. Liu, H. Zhou, S. Zhou, H. Zhang, A. Feng, C. Jian, J. $\mathrm{Hu}, \mathrm{W}$. Gao and J. Yuan, Macromolecules, 2014, 47, 2938-2946.

113. D. Han, O. Boissiere, S. Kumar, X. Tong, L. Tremblay and Y. Zhao, Macromolecules, 2012, 45, 7440-7445.

$114 . \quad$ B. Yan, D. Han, O. Boissiere, P. Ayotte and Y. Zhao, Soft Matter, 2013, 9, 2011-2016.

115. Q. Yan and Y. Zhao, J. Am. Chem. Soc., 2013, 135, 16300-16303.

116. Q. Yan, H. Zhang and Y. Zhao, ACS Macro Lett., 2014, 3, 472-476.

117. K. Jie, Y. Zhou, Y. Yao, B. Shi and F. Huang, J. Am. Chem. Soc., 2015, 137, 10472-10475.

118. L. Li, P. Rose and P. K. Moore, Annu. Rev. Pharmacool. Toxicol., 2011, 51, 169-187.

119. M. Zelzer, S. J. Todd, A. R. Hirst, T. O. McDonald and R. V. Ulijn, Biomater. Sci., 2013, 1, 11-39.

120. G. J. M. Habraken, M. Peeters, P. D. Thornton, C. E. Koning and A. Heise, Biomacromolecules, 2011, 12, 3761-3769.

121. A. R. Rodriguez, J. R. Kramer and T. J. Deming, Biomacromolecules, 2013, 14, 3610-3614.

122. P. S. Pramod, K. Takamura, S. Chaphekar, N. Balasubramanian and $M$. Jayakannan, Biomacromolecules, 2012, 13, 3627-3640.

123. D.-S. Guo, K. Wang, Y.-X. Wang and Y. Liu, J. Am. Chem. Soc., 2012, 134, 10244-10250.

124. J. K. Oh and J. M. Park, Prog. Polym. Sci., 2011, 36, 168-189.

125. J. Hu, T. Liu, G. Zhang, F. Jin and S. Liu, Macromol Rapid Commun., 2013, 34, 749-758.

126. H. Ai, C. Flask, B. Weinberg, X. T. Shuai, M. D. Pagel, D. Farrell, J. Duerk and J. Gao, Adv. Mater., 2005, 17, 1949-1952.

127. H. Oliveira, E. Pérez-Andrés, J. Thevenot, O. Sandre, E. Berra and S. Lecommandoux, J. Control. Release, 2013, 169, 165-170.

128. M. Krack, H. Hohenberg, A. Kornowski, P. Lindner, H. Weller and S. Förster, J. Am. Chem. Soc., 2008, 130, 7315-7320.

129. K. T. Kim, J. Zhu, S. A. Meeuwissen, J. J. Cornelissen, D. J. Pochan, R. J. Nolte and J. C. van Hest, J. Am. Chem. Soc., 2010, 132, 12522-12524.

130. D. A. Wilson, R. J. Nolte and J. C. van Hest, Nat. Chem., 2012, 4, 268-274.

131. S. A. Meeuwissen, K. T. Kim, Y. Chen, D. J. Pochan and J. van Hest, Angew. Chem. Int. Ed., 2011, 50, 70707073.

132. P. Van Rhee, R. Rikken, L. Abdelmohsen, J. Maan, R. Nolte, J. van Hest, P. Christianen and D. Wilson, Nat. Commun., 2014, 5, 5010.

133. R. S. Rikken, H. H. Kerkenaar, R. J. Nolte, J. C. Maan, J. C. van Hest, P. C. Christianen and D. A. Wilson, Chem. Commun., 2014, 50, 5394-5396.
134. S. M. Kuiper, M. Nallani, D. M. Vriezema, J. J. Cornelissen, J. C. van Hest, R. J. Nolte and A. E. Rowan, Org. Biomol. Chem., 2008, 6, 4315-4318.

135. D. M. Vriezema, J. Hoogboom, K. Velonia, K. Takazawa, P. Christianen, J. Maan, A. E. Rowan and R. J. Nolte, Angew. Chem. Int. Ed., 2003, 115, 796-800.

136. R. J. Peters, M. Marguet, S. Marais, M. W. Fraaije, J. van Hest and S. Lecommandoux, Angew. Chem. Int. Ed., 2014, 53, 146-150.

137. K. Langowska, C. G. Palivan and W. Meier, Chem. Commun., 2013, 49, 128-130.

138. K. T. Kim, J. J. Cornelissen, R. J. Nolte and J. van Hest, Adv. Mater., 2009, 21, 2787-2791.

139. T. Einfalt, R. Goers, I. A. Dinu, A. Najer, M. Spulber, O. Onaca-Fischer and C. G. Palivan, Nano Lett., 2015, 15, 7596-7603.

140. M. Spulber, A. Najer, K. Winkelbach, O. Glaied, M. Waser, U. Pieles, W. Meier and N. Bruns, J. Am. Chem. Soc., 2013, 135, 9204-9212.

141. X. Wang, J. Hu, G. Liu, J. Tian, H. Wang, M. Gong and S. Liu, J. Am. Chem. Soc., 2015, 137, 15262-15275. 


\section{Hailong Che}

Hailong Che received his M.Sc. in chemistry from Tsinghua University, in 2015. During his master's research, he focused on stimuli-responsive polymeric materials. Currently he is a Ph.D. candidate in the Department of Bio-organic Chemistry at Radboud University. He is working on bio-inspired functional compartments under the supervision of Prof. Jan van Hest.

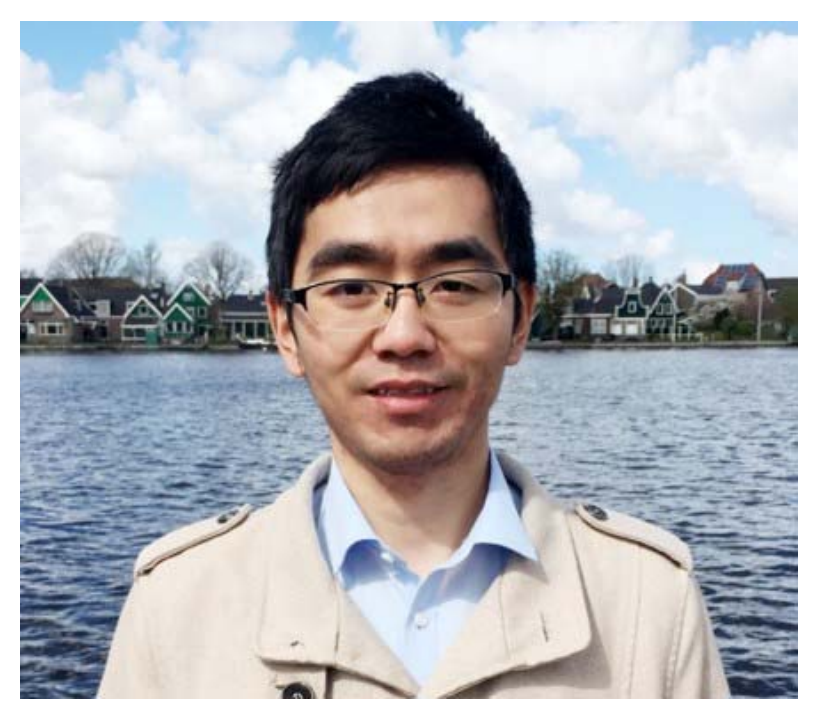




\section{Jan van Hest}

Jan C.M. van Hest obtained his PhD degree in 1996 at the Eindhoven University of Technology under guidance of Prof. Bert Meijer. As a post-doctoral researcher he investigated the incorporation of noncanonical amino acids via protein engineering under supervision of Prof. David. Tirrell, at the university of Massachusetts in Amherst.

He was appointed in 2000 as full professor at the Radboud University Nijmegen to set up a group in bio-organic chemistry. His current interests focus on translating natural structural concepts into bioinspired materials with the aid of state of the art organic and polymeric chemistry techniques and protein engineering.

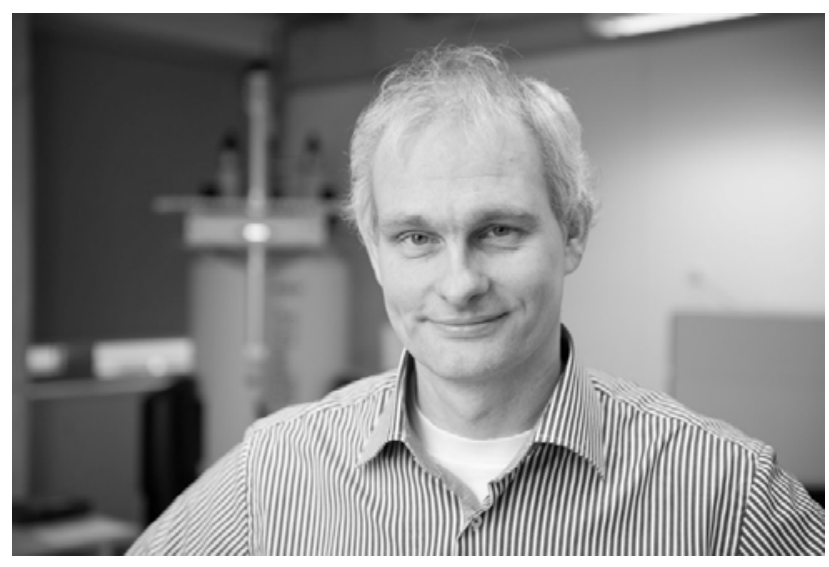

